\title{
ARRANGEMENT OF TERRITORIAL DEVELOPMENT PREDICTION
}

A perfect image of a territorial economic system predetermines the substance of economic and geographic prediction. Methodology of such prediction is search for coordination vectors regarding various aspects of territorial development, including management.

\section{Starting points}

R. Ackoff and F. Emery write: "A distinguishing feature of people and certain social systems, with people being part of them, is the fact that they may aspire to obtain results and states, which are impossible to be obtained, and they are well-aware of that. The point is that it is advancement towards such unattainable states that bring satisfaction to such people. Such advancement is called progress, and a finite state is called ideal" [1, p. 227]. Indeed, necessity to predict is immanent in man and society; that is a form of activity subject to thinking regularities, as well as material and spiritual needs. Prediction is constructive due not so much to soothsaying, as to sequencing inductive inferences referred to progress and attending problems.

Development of intellectual process methodology, systematization of methodologies and operational instrument of future projection resulted in the aggregate in establishment of prognostics - a branch of science with proper undefined concepts that interpret types and principles of prediction - develop prediction technology with a glance to object properties and information value, suggest specific means of prediction result verification [2]. Therefore, prediction does not fall outside the scope of science (that is not fortune-telling or astrological prediction). It is integral to theory and methodology. Theory generates a perfect image of the real world, while practice gives ground to the real world proper. The perfect (desired) and the real (existing) are integrated into cognitive standards - methodologies [3]. Prediction stand is socio-technical. Its substance is integration of various types of knowledge and their projection on the plane of organizational and managerial activity. Generally, three following types of knowledge are developed and utilized: 1) about controllable systems' life, 2) about manager systems' life and forms of organization of such systems; 3 ) about ways of integration of the objective and subjective, natural and artificial [4].

\footnotetext{
${ }^{1}$ The paper is completed within the framework of the Programme by the Presidium of the RAS "Fundamental problems related to spatial development of the Russian Federation: interdisciplinary synthesis".
}

A subject of management (manager structures) takes part in organization of social system development in a specific way. On the one hand, it is isolated from the system, as, for instance, a designer is isolated from the construction object; on the other hand, it is a part of the system proper, as it is involved by standard in all the stages of future projection through organizational and technological forms (laws, legal and standard acts, specific documents); it bears responsibility for the decisions made. Such duality is predetermined by an active position of people regarding their future.

Subjective factor and management agent activity arrangement are devoted much attention to in the process of development of prediction scientific basis during the last few years. That is proved by, for instance, materials of the international conference "Way to the future - science, global issues, visions and prospects" (Moscow, Institute of applied mathematics named after M.V. Keldysh, November 26-28, 2007). Thus, V. S. Stepin emphasizes the fact that "activity ceases to be an external factor for self-developing systems, but it acts as a process-component involved in the development" [5, p. 11]. E. N. Knyazeva notes: "Constructivism in knowledge and practice is an approach considering that man does not so much reflect the outside world through his perception, thinking and activity, as he actively creates and develops it" [6, p.2]. If we shift the given statements into the scope of scientific prediction, particular importance of a scientist's outlook, his original creed, membership of a specific scientific school, etc. are to be mentioned once again. Prediction results depend on that, and such dependence is already seen when selecting a goal and values. Value guidelines should be stated in an explicit form; it is also required to articulate certain notions;

- goal-setting - manager (researcher) expectancies;

- goal-defining - adjustment of expectancies subject to specific conditions;

- goal-implementation - selection of specific means to solve the key problems.

At this point it would be well to proceed from the philosophical and methodological interpretation of the "goal" category, as well as the difference between goal-directedness in an objective sense and dedication in a subjective sense. ${ }^{2}$

${ }^{2}$ In the book by R. Ackoff and F. Emery "About purposeful
systems" [1] the general idea is as follows: the future can be the 
Goal-directedness is predetermined by people's efforts to enhance the properties and qualities of the social systems they belong to. Therefore, the mentioned properties and qualities, as well as people proper, become, in essence, the main subject of prediction.

\section{Territorial development}

We determine territorial development as progressively directed change of the spatial pattern of national economy with an objective to create an optimal environment for people's life; that is transformation of "non-territory" into "territory" and transfer of territory from one quality into another; that is an economic and geographical process of complication and transformation of the economic space, generation and qualitative transformation of territorial economic systems [7].

The mentioned definition allows for stands by many geographers and economists focused on the concepts of interpenetration of the natural and social, on convergence of geographic and economic thinking, which makes it possible for the scientists to consider territorial development as a consistent socio-economic-geographic process with no contradiction. Therewith, territory is presented in three major aspects: as a spatial basis for activity, as a bearer (container) of resources and as a specific socio-economic reality that differs from enterprises and branches in terms of functions. Correspondingly, economy is interpreted as a complex socio-natural self-organizing system with a specific territorial profile.

Any economic system can be considered territorial in case if a special factor of its development is one of the principal, and its functions are directed towards satisfaction of wants of such a society as a territorial community. Socio-economic geography and regional economy most commonly study integral systems - local and regional. The present paper is dedicated mostly to a regional economic system (RES), in which, similarly to a local one, man and his residence are primary backbone elements.

Prediction of RES development cannot be efficient without information about the system proper. In our opinion, RESs should be comparatively integral in state-political, economic and ethnosocial respects. In line with the national economic geography traditions formed as far back as the prerevolutionary period and the GOELRO plan time, an optimal (high-level) RES can be presented as a major (large) socio-economic territory, which is self-reliant in terms of generation and functioning of productive

way it is projected by a management agent. forces, development of life cycles of different nature: technological, natural, social etc. Productive forces become social within the limits of such a territory; the most comprehensive coordination of natural resource, production, settlement, infrastructural and administrative (management) subsystems occurs in the territory.

Such $a$ standard territory potentially claims to be a supporting structural unit of the country. That is a "regional standard" ${ }^{1}$ with comparable natural, economic and human development potential.

A standard territory is exactly a theoretically perfect image of a supporting socio-economic area in our country. According to the logic of the diagram (Fig. 1), a state with all the RES components being adjusted in accordance with each other (horizontally and vertically) is predicted. The following question that arises from the given diagram is of methodological interest: what should be optimized first?

The authors consider that family or household represent the given optimization unit. The given option falls within the scope of the ultimate priority of the domestic policy of Russia - preservation of the population, ${ }^{2}$ as well as treatment of an area proper as developing population with motivated behavior and focus on naturalistic practicability. State of local and regional economic systems, and, ultimately, the whole major socio-economic area depends on the way a family will be and a household will be organized. Motion from the desired (statutory) state of the primary unit of the society towards a territorial system of a particular hierarchic level is multidimensional, and it requires regulation of development resources of all components given in Fig.

Along with that, consideration must be given to the fact that the point of such motion is not only in a number of people inhabiting a particular territory and resource capability for people's life activity, but also in qualitative parameters of entire territorial economic systems. Let us mention substantial desired parameters of a RES.

Social amenities. The given parameter sets a social component of development as a priority. Not only conventional showing in terms of demography, consumption level, social infrastructure, but also those relatively new rates, such as social stratification, deprivation, degradation to lumpens, social tension etc. should be taken into consideration under the present-day conditions.

\footnotetext{
${ }^{1}$ An effort to express the given standard in numerical terms was first made by B.N. Zimin [8].

2 The given vector of domestic policy of tsarist Russia was first stated by M. V. Lomonosov; and for modern Russia - by A. I. Solzhenitsyn.
} 


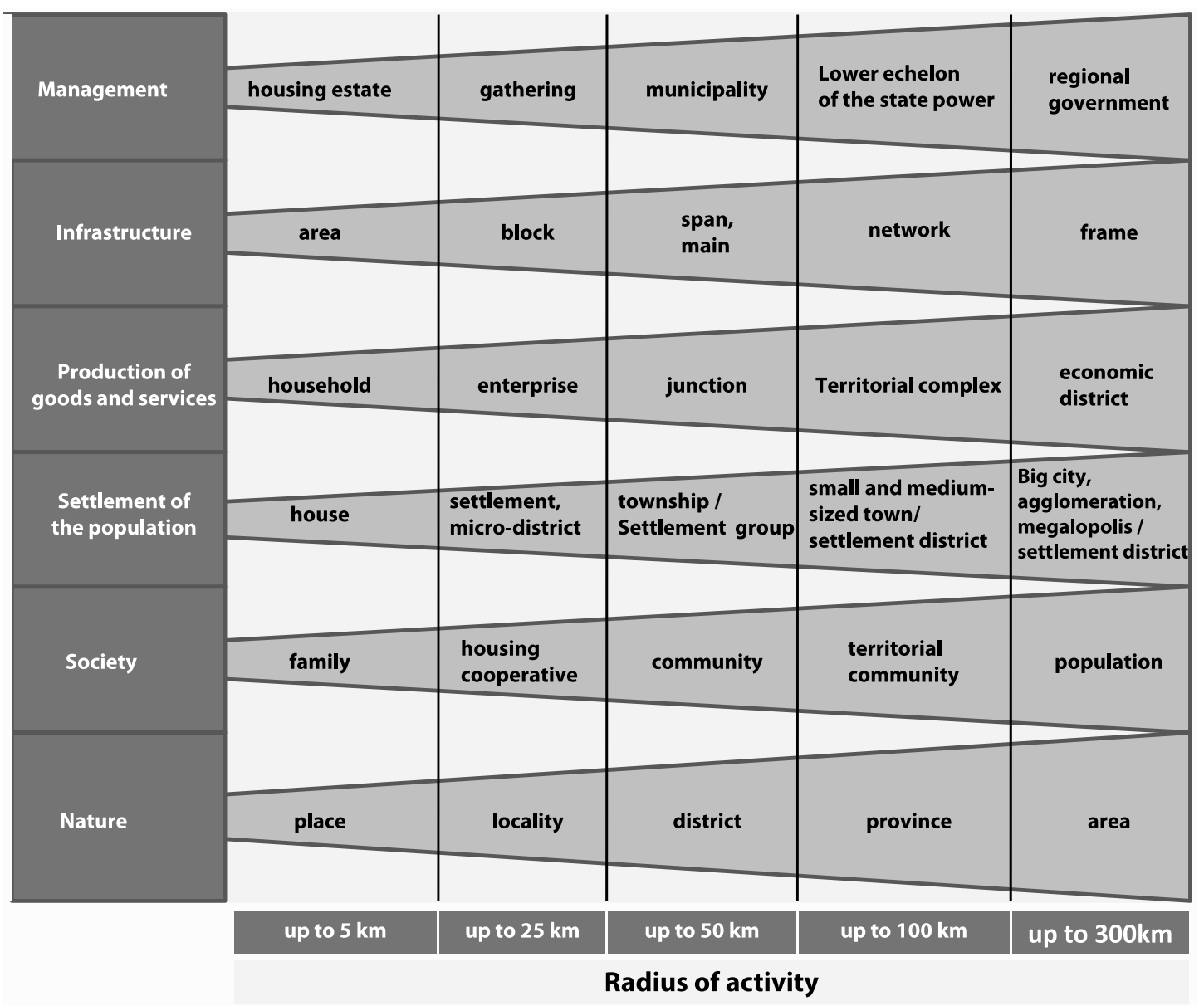

Fig. Perfect (theoretical) image of a major socio-economic district

Multiple-structure. A RES structure is assumed to be multiple-aspect, and it reflects diversification of socio-economic relations. Multiple-structure can be represented in different aspects, for instance, functional (complex of technological, economic, social, ecological and information subsystems), attributive (complex of nature, production, settlement subsystems) etc. Variety of structures may be included in the same territorial system, and there can be multitude of manifestations of one and the same structure [9].

Problem-focused. Initially, people's efforts aimed at negotiation of difficulties in the path of the goal to be reached are taken into account. The problem is located through unsatisfactory state of goal-seeking systems [1], and it is solved by way of new knowledge acquisition. Prediction is essential to emanate from the fact that one and the same problem appears differently at different stages of resolution: at first it appears as a scientific research problem; then - scientific-applied, and finally, - economic-organizational. The given life course of the problem complies with the technological diagram of prediction.

Sustainability. That is the main result of socioeconomic system complication, and one of its most contradictory properties. The desired state of dynamic stability is unattainable in principle; it is prediction of secure development and anticipatory action conditions that is of interest. ${ }^{1}$ In this respect, shall we note that pre-crisis and post-crisis measures aimed at securing relative sustainability are of different substance. In the first case the matter involves constructive prediction of the forthcoming, in the second case - reaction to what happened, elimination of stagnation consequences.

Complementarity. A regional system is involved in the national economy and it establishes subordination and coordination relations with it.

Self-development. It bears on capability of the social system for self-organization and self-control. However, that does not signify total autonomy, isolation, separatism. In this case "self" refers, first of all, to active stand of regional governments regarding development of socio-economic relations.

The six properties listed form prediction ground for territorial development as a whole (without dissipation into separate objects, such as enterprises or

\footnotetext{
${ }^{1}$ For instance, the state of equilibrium prices for goods is unattainable; however, the appropriate balance theory is substantial for market relations control.
} 
branches). Even more attention is focused on territoriality provided the prediction subject includes specific attributes of space studied by geography. Geographers-economists deal with the following attributes: 1) heterogeneity; 2) order of sizes and forms of allocated objects; 3) geographic integrity; 4) regularity of geographic occasions in time; 5) variability; 6) continuity and discreteness; 7) relationship to the environment (reproduction of geographic resources); 8) response to external influence [10].

Due to reactivated research into spatial economics, we have taken particular notice of the northern periphery. Focality and dispersibility of location of economic activity and population settlement are specific of the given territory, as well as "spatial exclusion", i.e. elimination of a certain territory from normal life conditions from socio-economic relations and regional development processes owing to insufficient territorial capital [11]. Hence, "instructions for the future" follow: to withstand undesirable space distortion, take steps aimed at restoration and upgrading of the space, involve the periphery in the process of innovation development.

\section{Arrangement of regional economic system projection}

Planning of the future includes two aspects: ontological, i.e. referred to description of the system proper; and gnoseological, i.e. determining goal transformation regarding the forthcoming activity. Both aspects take account of interaction of an object and subject of management, and they affect generation of technological projecting phases. The table demonstrates projection arrangement as we perceive it; it includes the following cycles: analysis, concept definition, planning a strategy, programming, monitoring.

Analysis. Conventionally, analysis is interpreted as decomposition of a whole into parts in order to give scientific interpretation to the structure of the object under research, to reveal its internal structural and functional correlation, and to search for synergic effect. In this case an object is specified according to the scheme: material, composition, structure, functions of the component parts and internal processes, system generation. Such analysis is also applied for study of socio-economic objects. A typical RES is very diverse in terms of material; it integrates three blocks - nature, population and economy, and five base subsystems - technology, economy, social development, ecology and information science. Correspondingly, their functions are also analyzed: innovative, efficient production and social justice, reproduction of natural resource potential and environmental protection, communication development. All that is projected onto the chief target function of the RES as a whole - creation of favourable life environment and maintaining an optimal life-support system in a particular territory.

When specifying development lines, a RES quality change mechanism with relative quantitative indices (for instance, change of energy sector types and fixed capital reproduction, cycles of transportation service generation etc.) is analyzed. Trends of certain processes, strong and weak points in the system, external impulses impediments are revealed. In the issue of the analysis assessment of social change is made; it gives an insight into the progress lines, and guidelines (orders) specifying future activity vectors are defined.

It is not only an object that is analyzed, but also previous steps aimed at its development. A researcher (a team of researchers) is to be aware of the fact that generally predictions have already been done by the moment he initiates his own prediction. That is also true for organizations making official decisions and executing strategies as state documents. There is a notion of "prediction market" existing in the European countries. Availability of the prediction market provides a choice; along with that, to select what most complies with planning and projection problems, purposeful analysis is required. Such a market filled with various institutions and centers exists in our country as well; in addition, plenty of official strategic documents are stockpiled.

Let us mention another peculiarity of the analysis "for prediction". Single analysis for each cycle of execution of prediction elaboration is made: diagnostic - for concept-defining, priority problem analysis - for strategy-setting; analysis of programming - for monitoring trend analysis.

Concept-defining. At the interface between theory and practice an RES goal is set. The subject of management selects value guidelines of development and defines a position in relation to the given guidelines on the basis of the previous analysis. The purpose of concept-defining is creation of images of the future, desirable state of the system being the purpose of its development. Hence, the function of concept-defining is goal-defining, promotion of activity goals. As a result of concept-defining, there is a set of goals (ideals) and a goal-specified type of RES development, the vector of movement.

Strategy-setting is concerned with transition from goal-defining to goal-setting and it solves the main problem - generation of means to accomplish a perfect condition of the system. Generation of means is, in fact, system projecting; therefore, strategy-setting (along with programming) is a reference point of technology of RES projection. 
Content of the main technological cycles of programming (system projecting)

\begin{tabular}{|c|c|c|c|c|c|}
\hline Content parameters & Situation analysis & $\begin{array}{c}\text { Goal-defining } \\
\text { Concept-defining }\end{array}$ & $\begin{array}{c}\text { Goal-setting } \\
\text { Planning a strategy }\end{array}$ & $\begin{array}{c}\text { Goal- } \\
\text { implementation } \\
\text { Programming }\end{array}$ & Monitoring \\
\hline Function & $\begin{array}{l}\text { Determination of } \\
\text { the present state of } \\
\text { the system. }\end{array}$ & $\begin{array}{l}\text { Creation of } \\
\text { visions of } \\
\text { the future } \\
\text { as desirable } \\
\text { (perfect) states of } \\
\text { the system. What } \\
\text { is desired? }\end{array}$ & $\begin{array}{l}\text { Defining key means } \\
\text { of goal attainment. } \\
\text { What is to be done? }\end{array}$ & $\begin{array}{l}\text { Defining tactical } \\
\text { means of goal } \\
\text { attainment. } \\
\text { Ways to do that. }\end{array}$ & $\begin{array}{l}\text { Control over system } \\
\text { organization. } \\
\text { What was obtained? }\end{array}$ \\
\hline $\begin{array}{l}\text { Factors (what we are } \\
\text { guided by, what is to } \\
\text { be specified) }\end{array}$ & $\begin{array}{l}\text { 1. Available object } \\
\text { 2. Lines of } \\
\text { development } \\
\text { Description of the } \\
\text { object, material, } \\
\text { composition, } \\
\text { structure, } \\
\text { functions and } \\
\text { constituent } \\
\text { processes of } \\
\text { subsystems }\end{array}$ & $\begin{array}{l}\text { Values - system } \\
\text { properties, } \\
\text { which meet the } \\
\text { demands of a } \\
\text { subject. } \\
\text { Stands - ways } \\
\text { to implement the } \\
\text { values }\end{array}$ & $\begin{array}{l}\text { Main lines of } \\
\text { development of the } \\
\text { country. } \\
\text { Sources of } \\
\text { development }\end{array}$ & $\begin{array}{l}\text { Problem-setting, } \\
\text { selection of priority } \\
\text { problems }\end{array}$ & $\begin{array}{l}\text { Assessment of } \\
\text { changes occurred } \\
\text { in the system, their } \\
\text { effects }\end{array}$ \\
\hline $\begin{array}{l}\text { Key description } \\
\text { features (content } \\
\text { attributes) }\end{array}$ & $\begin{array}{l}\text { Vectors of } \\
\text { development } \\
\text { (D), nuclear } \\
\text { process of D, D } \\
\text { path parameters, } \\
\text { process trends } \\
\text { of system and } \\
\text { subsystem D, } \\
\text { strong and } \\
\text { weak points } \\
\text { of D, external } \\
\text { opportunities and } \\
\text { impediments }\end{array}$ & $\begin{array}{l}\text { Visions of the } \\
\text { future in the form } \\
\text { of predictions, } \\
\text { including: } \\
\text { limits, growth } \\
\text { of development } \\
\text { rates, process } \\
\text { variants, } \\
\text { alternatives, } \\
\text { turns, qualitative } \\
\text { leaps, break } \\
\text { points, growing } \\
\text { points }\end{array}$ & \begin{tabular}{|l|} 
1. Lines of \\
development as a \\
result of the goal \\
decomposition - \\
total of problems \\
2. Sources of \\
development - new \\
formations for the \\
process organization: \\
types of organization \\
(production, social, \\
territorial), social \\
and material and \\
technical bearers \\
of new formations \\
(institutions, \\
population \\
groups...)
\end{tabular} & $\begin{array}{l}\text { Transition to } \\
\text { operational space of } \\
\text { practice } \\
\text { 1. Priority problems } \\
\text { solved through } \\
\text { programming } \\
\text { 2. Structuring } \\
\text { of the types of } \\
\text { programming } \\
\text { activity concerned } \\
\text { with: } \\
\text { a) subsystem } \\
\text { generation, } \\
\text { b) system design } \\
\text { cycles (preparatory, } \\
\text { main and attendant } \\
\text { activity) }\end{array}$ & $\begin{array}{l}\text { Trend analysis } \\
\text { 1. Rates specifying } \\
\text { development path, } \\
\text { лун subsystem } \\
\text { processes } \\
\text { 2. System state } \\
\text { sections: pre- } \\
\text { programming (at } \\
\text { an analysis stage), } \\
\text { prognostic (at the } \\
\text { stage of concept- } \\
\text { defining), post- } \\
\text { programming (after } \\
\text { taking key steps) }\end{array}$ \\
\hline $\begin{array}{l}\text { Result (at the } \\
\text { output) }\end{array}$ & $\begin{array}{l}\text { Assessment } \\
\text { of progressive } \\
\text { changes in the } \\
\text { system. } \\
\text { Definition of } \\
\text { guidelines (What } \\
\text { is to be done?) }\end{array}$ & $\begin{array}{l}\text { Expanded view } \\
\text { of a development } \\
\text { goal in the form } \\
\text { of prediction }\end{array}$ & $\begin{array}{l}\text { Strategic objectives } \\
\text { of development. } \\
\text { Key means of } \\
\text { problem-solving }\end{array}$ & $\begin{array}{l}\text { Package of measures } \\
\text { and objectives } \\
\text { approved in terms } \\
\text { of resources, terms, } \\
\text { rates and executors }\end{array}$ & $\begin{array}{l}\text { Estimate of } \\
\text { efficiency of the } \\
\text { programming } \\
\text { activity }\end{array}$ \\
\hline
\end{tabular}

While concept determines a type of development, then strategy determines a type of influence securing advancement. The given influence is aimed at system complication in the mode of "advancing reflection". It assumes account for directions and trends of internal self-development, and at the same time it provides by specific means new opportunities, which are unattainable under «natural» development (use of only internal possibilities).

As a part of means that arrange the projected system, let us mention directions and sources of devel- opment. The main directions of RES development are set as a result of decomposition of the general goal into a number of tasks. Sources are new formations, which arrange, or, as they say, localize the development. They are identified as structures-attractors in the theory of self-organization (synergy). In terms of "material", that is forms and methods of organization of subject activity, i.e. specific processes. New types of organization of economic relations, social processes, innovation technologies, and production can be considered as structures-attractors. Material, 
technical and social carriers of new formations are public institutions, social groups, different network structures (information, transport, technological, etc.).

As a result of strategy-setting, there is a set of tasks aimed at concept realization, and a system of key means to advance the prospective future.

Programming. At the given stage is specified by generation of tactical means of goal attainment and goal-implementation. Programming is also specified by attainment of an end result of system projection by specific means - development of a policy, i.e. a complex of purposes and activities and establishment of the required organization structures.

Major factors of programming are necessity to set strategic tasks and transfer administrative activity to a new operational domain - practice.

An initial step of programming is problem-setting. It is specified by necessity to define concretely the main directions of system development, transform general strategic tasks into particular and technical ones. Problem-setting is possible due to: 1) a degree problems are solved, 2) a way they are solved. The first means that not any task poses a problem, but only the one that reflects a deadlock condition of development and provides no clear decision. Problem in the context of the present research is a bottleneck in solving strategic tasks; it is revealed at priority selection and it requires development of corresponding tactical means within the framework of a specific program.

Transition into a new operational domain of administrative activity - economic practice - is connected with an essence of goal-implementation. That is transition from theory to practice, from thinking to action. Transition of work of a manager to reality is a key factor of organization of the given reality, i.e. organization of practical activity aimed at formation of a desirable condition of the system. Programming is focused on the process of activity, it is permanent, and it develops step by step.

That, in turn, requires, first, structuring of practical activities; second, use of an organizational and technological unit of a specific type corresponding to the new operational domain.

It is lawful to consider measure as such an organizational and technological unit. On the one hand, it is action, a necessary and specific step towards goal implementation; on the other hand, it is a materialized matrix coherence, a primary element of the program activity. A form of measure is specified by particular kinds of activity. It can be symbolic, in the form of a document - a standard act, agreement, contract, project, cadastre etc., and also in the form of industrial-technological operation - a geological search, reconstruction, new construction and so forth. Modification to measures is tasks given to participants of the program.

A matrix of the program measures that are coordinated in time, resources and basic indicators represents the basic result of programming.

A programmed control potential in Russia is rather high. The positive factors are: a harmonious programming theory, methodology, legal maintenance (federal law, program passport). However, the potential is reduced due to the following negative phenomena: no effect with a great number of programs; not all the documents referred to as the program are the program, the most part of them are concepts or strategies at best. The cause of inefficiency is seemingly in weak financial support. The reason lies on the surface. However, there is a belief that the majority of programs would hang even with sufficient financing (still greater wrongdoing of inefficient use of slender means). One cannot but note drawbacks of development as well: the problem (essence, nature, scale) is not comprehended; lack of coordination of interests between the participants of problem resolution; low level of team work; assessment of program efficiency was not carried out properly.

Drawbacks of program implementation are great number of private structures, which counteract implementation of general programs, reckoning on federal support, lack of finance accumulation mechanisms on the basis of cooperation, lack of program implementation monitoring.

Monitoring. The objective of monitoring is to control the process of projection and organization of the economic system; the mentioned process is a complex of directional influences. Therewith, influence results based on fixation of degree of changes in the system and their consequences are appraised. In addition, trends of the key processes in the system and its subsystems are revealed. The results and trends are considered when the goal and strategy of the system development are being adjusted, which allows resuming the projection cycle and securing continuity of command.

Tracing results of projected (regulated by the program) development is a function of directional monitoring, as opposed to general monitoring that mostly register changes. An essence of such monitoring analytical and prognostic, it reflects proximity (or distance) of actual changes to a desirable condition, the purpose of development.

Directional monitoring should bear on indicators, which specify lines of the system development. 
The monitoring data array is generated at different stages of projection and RES organization, namely, during analysis and concept-defining, as well as after the key program steps. Thus, such monitoring is to reflect pre-programming, desirable (predicted) and post-programming condition of the system. Comparison of the conditions affords a basis for assessment of efficiency of the whole projection cycle and system organization, and it can be registered as a general package including documents related to government control of RES development.

Thus, the considered stages of RES development organization differ in terms of the purposes, substance and results. They are the basic elements of the territorial administration technology based on systemic, organizational and activity approaches. We consider the given technology to be the most productive in the context of development of the main program documents referred to state planning of territorial development.

\section{Organization of territorial development practice}

Territorial development includes many types of practice. Some of them are apparent: improvement, land management, nature management and environmental protection, location of economic activity, construction of transport, power, hydroeconomic and information communications, municipal engineering and population settlement. Others seem to be distant from a territory, but nevertheless they characterize such social entities of the territory as human development, physical and spiritual potential of a person (health, education, creativity, culture, spirituality).

It is possible to present cumulative practice of territorial administration as economic and geographical activity in the form of geopolitics, regional policy, statistics, geoinformatics, cartography, territorial planning, zoning, district and landscape design, geographical and ecological appraisal.

If the above mentioned is considered from the point of view of prediction, then, apparently, a problem of conformity of forms of organization of economic and geographical activity to a desirable condition of territorial economic systems is to be particularly emphasized. Let us define two problems:

- Whether the content of previously used and currently developed strategic documents corresponds to what should be reflected in the given documents?

- Whether organization of territorial development control corresponds to the general tasks?

The first problem is not new for the authors. We considered it in connection with the analysis of doc- uments referred to planning and long-term prediction, for instance, the Complex programme of scientific and technical progress for 20 years (regional profile) and Plans of development and distribution of productive forces for 15 years. At this point we have noted certain discrepancy between initial orientation of documents to solving specific problems of the technological progress and distribution of productive forces and their general substance. Key problems of the technological progress and distribution of productive forces were repeatedly replaced by other socio-economic development issues. The latter appeared one-to-one in both the Complex program, and the Plan. It was also mentioned that there was substitution of the notion of "productive forces" with a concept "production"; therefore, "force" was not measured anyhow, and its components (concentration, specialization, cooperation, combination, integration) were overlooked.

One cannot but notice that shortcomings of the past years pass to the present. There is abundance of various indicators in the strategic documents, and, as a result, it is difficult to understand the point of goal-defining, goal-setting and goal implementation. The same can be said about the policy related to innovation and modernization.

To answer the second question, let us cite V.V. Vladimirov, a well-known expert in municipal engineering management and territorial development. In the given domain he discovers much inconsistency of architectural, planning, legal and economic nature, and, what is most important, lack of systemacy in territorial management. "In Russia, beyond any reasonable doubt, there should also [as well as in many western countries (author's remark)] be full-fledged executive chain of command dedicated to solving strategic problems related to development of cities and municipal engineering. Therefore, the system of control of territorial development and municipal engineering is required that it be reformed at the federal level" [12, p. 61]. It is suggested that a Council for territorial, city development and environmental protection, as well as a Ministry for organization of territory, municipal engineering and architecture is established within the given system at the federal level; at the level of a constituent entity of the Federation - a Council for territorial development, municipal engineering and environmental protection of a region (republic, territory, district), Committee (department, administration) for territorial development, municipal engineering and architecture and department for municipal engineering and architecture of administrative regions (district and regional municipalities). 
In our opinion, the executive chain of command offered by V.V. Vladimirov corresponds to specific character of territorial development, as well as to the functions of the types of economic and geographical practice mentioned above. Indeed, at present there is no governing body that would use and develop the potential of geoinformatics, cartography, regional and landscape design, geographical expertology and of some other components of territorial development control at best.

A scheme of territorial planning became one of the basic documents in the system of regional government. It reflects a strategy of socio-economic development of a region (republic, territory, district) and corresponding programs in reference to a territory, as well as association of the predicted with actual conditions of the area. Theoretical interpretation of the given documents [13] and the first experience of their formulation [14] give hope that the given documents will be constructive. As we see it, there should be more efficient replacement of the Scheme of regional planning, which was earlier included in the system of regional planning. At the same time, the scheme of territorial planning does not replace local documents - master plans and regional planning projects.

Thus, prediction of territorial development should be embedded in systemically organized management and relative state documents. Without that it is impossible to secure interfacing of a perfect image of the projected future with the reality.

\section{References}

1. Ackoff, R., Emery, F. (1974). About purposeful systems. Translated from English. Ed. by I. A. Ushakov. Moscow: Sovietskoye radio. $272 \mathrm{p}$.

2. Prognostics. Terminology. Ed. by V. I. Siphorov (Corresponding member of the Academy of sciences USSR), issue 92, Moscow: Science, 1978. 32 p.

3. Lazhentsev, V. N. (2010). Interconnection of theory and practice. An example of methodology of economic and geographic research. Komi Scientific Center UB RAS bulletin, 3. pp. 98-106.

4. Shedrovitsky, G. P. (1992). "Natural" and "artificial" in socio-technocal systems. Methodology issues, 1-2. pp. 3-11.

5. Stepin, V. S. Self-developing systems and philosophy of synergy. Materials of the international conference "Way to the future - science, global problems, dreams and hopes" (Moscow, November 26-28, 2007). Retrieved from: http:// nonlin.ru/node/163.

6. Knyazeva, E. N. World designed in a synergic way. Materials of the international conference "Way to the future - science, global problems, dreams and hopes" (Moscow, November 26-28, 2007). Retrieved from: http://spknrdynmov. narod.ru/KnyzevaElena/htm.

7. Lazhentsev, V. N. (1996). Territorial development. Methodology and experience of regulation. St.-Petersburg: Science, $109 \mathrm{p}$.

8. Zimin, B. N. (1993). Minor developed countries of the Western Europe - theoretical results of researches. RAS Bulletin, 2. (Geography). pp. 95-104.

9. Kotlyakov, V. M., Trofimov, A. M., Seliverstov, Y. P., Rubtsov, V. A. (1999). The notion of a territorial system structure and approaches to modeling of such a structure. RAS Bulletin, 5. (Geography). pp. 17-24.

10. Prediction in economic geography: teaching aid. Kazan: the Kazan State University Publ., 1990. 103 p.

11. Dmitriyeva, T. E. (2009). Methodological context of space development of the Northern region. Economy of the NorthWest. Problems and development prospect. 1(39). pp. 22-29.

12. Vladimirov, V. V. (2000). Management of municipal engineering and territorial development. Moscow: Department of information and publishing of the Russian Academy of Architecture and Construction Sciences, $92 \mathrm{p}$.

13. Territorial planning. New functions, experience, problems, solutions. Collected papers. Ed. by A. I. Chistobayev. St.-Petersburg: the St.-Petersburg State University Publ., 2009. $189 \mathrm{p}$.

14. Chistobayev, A. I., Krasovskaya, O. V., Skatershikov, S. V. (2010). Territorial planning at the level of constituent territories in Russia. St.-Petersburg: SPBSU, NPI “ENKO”, “Inkern” Publ. house. 296 p.

\section{UDC 338.984}

keywords: prediction, regional economic systems, vision of the future, project management, programming, practice of territorial development 